\title{
Versão abreviada da Escala Triangular do Amor: evidências de validade fatorial e consistência interna
}

\author{
Valdiney Veloso Gouveia \\ Patrícia Nunes da Fonseca \\ Jane Palmeira Nóbrega Cavalcanti \\ Pollyane K. da Costa Diniz \\ Luciana Chacon Dória \\ Universidade Federal da Paraíba
}

\begin{abstract}
Resumo
O presente estudo teve como objetivo conhecer os parâmetros psicométricos de uma versão reduzida da Escala Triangular do Amor. Especificamente, procurou-se reunir evidências de sua validade fatorial e consistência interna no contexto paraibano. Participaram 307 estudantes universitários da cidade de João Pessoa (PB), que mantinham um relacionamento heterossexual estável, com idade média de 23,4 anos ( $d p=6,22$; amplitude de 17 a 56 anos). A maioria foi do sexo feminino (69,4\%) e solteira (73\%). Os participantes responderam a Escala Triangular do Amor e perguntas demográficas. Os resultados apoiaram a adequação psicométrica dessa medida, que apresentou três componentes (rotação varimax; explicando 67,7\% da variância total), com Alfas de Cronbach satisfatórios: compromisso $(\alpha=0,88)$, paixão $(\alpha=0,87)$ e intimidade $(\alpha=0,86)$. As mulheres pontuaram mais em compromisso do que fizeram os homens. Estes resultados foram discutidos à luz da literatura, confirmando-se a adequação desta medida. Pesquisas futuras foram sugeridas.
\end{abstract}

Palavras-chave: amor; escala; triangular; validade fatorial; consistência interna.

\begin{abstract}
Brief version of the Triangular Love Scale: evidences of factor validity and reliability. This study aimed at knowing the psychometric parameters of a shorted version of the Triangular Love Scale. Specifically, it tried to joint evidences of its factor validity and reliability in the Paraibano milieu. Participants were 307 undergraduate students from João Pessoa (PB), which have a stable heterosexual relationship. Their mean age was 23.4 years old ( $s d=6.22$; ranging from 17 to 56$)$, most of them female $(69.4 \%)$ and single $(73 \%)$. They answered the Triangular Love Scale and demographic asks. Results support the psychometric adequacy of this measure, which showed three components (varimax rotation; accounting for $67.7 \%$ of the total variance), with satisfactory Cronbach's Alpha: commitment $(\alpha=0.88)$, passion $(\alpha=0.87)$, and intimacy $(\alpha$ $=0.86)$. Women scored higher than men in commitment. These findings were discussed based on literature, confirming the adequacy of the scale. Future studies were suggested too.
\end{abstract}

Keywords: love; scale; triangular; factor validity; reliability.

A contribuição da psicologia, no que se refere aos estudos da atração interpessoal, deflagrou especialmente a partir das décadas de 60 e 70 do século XX, afirma Bystronski (1995). Conseqüentemente, ocorreram modificações no conceito do amor, ou seja, segundo a autora, o amor até então era conceituado como uma atitude mantida por uma pessoa em relação a uma outra em particular, envolvendo predisposições para pensar, sentir e comportar-se de determinado modo relativamente àquela pessoa. Mais recentemente, os estudos sobre o amor passaram a compreender este sentimento como sendo algo multidimensional (Engel, Olson \& Patrick, 2002), além de considerar seu aspecto estrutural e dinâmico, ampliando a análise dos fenômenos de atração interpessoal (Alferes, 2002).

Frente a esta conjuntura recente, com o propósito de compreender as várias questões em torno desta temática, foram desenvolvidos modelos globais do amor (Bystronski, 1995), formando um conjunto articulado de noções sobre a evolução temporal do amor, chegando a quatro possíveis componentes deste fenômeno: o precisar do outro, o cuidado, a confiança e a tolerância. Além disso, foram igualmente construídas noções sobre as condições causais (como influenciam e são influenciadas pela interação e/ou eventos exteriores), bem como modelos onde foi possível compreender o amor por meio de classificações ou 
sistematizações (Alferes, 2002). Em uma revisão das principais vertentes teóricas no estudo científico do amor, Bystronski (1995) destaca quatro destes modelos: (1) os amores passional, pragmático e altruísta, (2) o comprometimento, (3) as cores do amor e (4) a teoria triangular do amor.

Dentro da evolução temporal, o amor passional enfatiza o aspecto precisar do amor, incluindo necessidades de afiliação e dependência, sentimentos de exclusividade, excitação sexual e paixão. Contrariamente ao amor passional, o amor pragmático é aquele relacionado com a confiança e tolerância. Ocorre entre adultos maduros e é comum em relacionamentos duradouros; além disso, é mais tranqüilo e, sobretudo, mais estável. Por fim, neste grupo, o indivíduo impelido pelo amor altruísta considera que é cuidando do outro e fazendo todo o possível pela sua felicidade que pode encontrar sentido e satisfação em sua própria vida (Alferes, 2002; Bystronski, 1995). O comprometimento é responsável por promover a estabilidade da relação, por isso mantêm a interação entre indivíduos, mesmo quando os fatores que favorecem sua adesão são fracos. Aqui, a satisfação é apresentada como suposto contribuinte para o fenômeno do amor (Adams \& Jones, 1997).

Nos modelos de análise sistemática, Bystronski (1995) destaca primeiramente as cores do amor. Apontada por esta autora como a teoria até então mais conhecida, essa taxonomia do amor baseia-se na pressuposição de que tal sentimento é um fenômeno plural. De acordo com a autora, foi por meio do psicólogo canadense John Alan Lee, na década de 1970, que o amor passou a ser estabelecido de modo classificatório por meio de uma analogia às cores. Portanto, assim como a preferência pelas cores, o estilo de amor de uma pessoa pode variar durante a vida e de uma relação para outra.

O grego e o latim foram as línguas nas quais Lee (1973, 1988) buscou os termos para compor sua classificação dos estilos de amor, formando um círculo fechado. Em sua tipologia, que é baseada fundamentalmente em dados de entrevistas, são identificados seis tipos principais de amor, divididos em dois grupos: (1) tipos primários: (a) Eros: chamados de amantes eróticos, o amor aqui começa sempre de forma avassaladora, pois o parceiro ideal é uma raridade; (b) Storge: estilo de amor em que o indivíduo se acostuma com o parceiro ao invés de apaixonar-se por ele, por este motivo, a relação romântica pode começar a partir de um relacionamento de pura amizade; e (c) Ludus: o amante lúdico espera que o amor seja prazeroso e não comprometedor; ele é na verdade colecionador de experiências de amor, que serão relembradas com prazer; e (2) tipos secundários: (a) Mania: diz respeito ao estilo obsessivo de amor, que é altamente volátil, alimentado por uma baixa auto-estima; (b) Pragma: compreende um tipo de amor realista e prático, sendo as ações guiadas pela "cabeça" mais do que pelo "coração"; e (c) Agape: é um tipo não egoísta de amor, sendo mais bem altruísta, caracterizado como o amor materno.

Além dos estilos anteriormente listados, fazendo uma analogia às cores do arco-íris, Lee $(1973,1988)$ admite a existência de estilos infinitos de amor, resultantes da combinação dos tipos primários e secundários. Estes podem variar de acordo com o tempo, as experiências e as características individuais e de personalidade da pessoa e de seu(sua) parceiro(a) (Hernandez,
1999; Hernandez \& Oliveira, 2003; White, Hendrick, \& Hendrick, 2004). Hendrick e Hendrick (1986) desenvolveram e validaram uma medida específica que contempla os seis tipos de amor descritos por Lee (1973), denominada Love Attitude Scale. Não obstante, quando realizada uma busca no website Google Acadêmico (2009) com o nome desse instrumento, percebeu-se que ele foi menos citado (77 citações) do que a Escala Triangular do Amor (155), cujo embasamento teórico é a seguir considerado.

Ainda na linha das análises sistemáticas do amor, incluise a teoria triangular do amor. Considerada a mais atual e utilizada em pesquisas no âmbito da psicologia, semelhante ao modelo teórico as cores do amor, fornece também taxonomias do amor (Bystronski, 1995; Hernandez \& Oliveira, 2003). Esta teoria foi proposta por Robert J. Sternberg, da Universidade de Yale, nos Estados Unidos (Sternberg, 1986, 1997, 1998). A partir da década de 1980, os trabalhos realizados por Sternberg sobre o amor tornaram-se fonte de referência teórica e empírica indispensáveis para os estudos que se propunham analisar o amor de maneira classificatória. Por este motivo, tal modelo teórico é especialmente exposto a seguir.

\section{Teoria Triangular do Amor}

De acordo com esta perspectiva, o amor pode ser classificado em três componentes principais: intimidade, paixão e compromisso, formando vértices de um triângulo (Alferes, 2002; Engel et al., 2002; Serrano \& Carreño, 1993; Sternberg, 1986). Este, por sua vez, é uma metáfora mais do que simplesmente um modelo geométrico. No contexto desta teoria, cada elemento manifesta aspectos diferentes do amor (Gao, 2001; Sternberg, 1986, 1998), como mostrados na Figura 1.

Intimidade (topo do vértice do triângulo). Este é um dos componentes dinâmicos mais valiosos. Refere-se àqueles sentimentos que promovem proximidade, vínculo e conexão nos relacionamentos amorosos. Incluem em seu campo de ação sentimentos que enaltecem, essencialmente, a experiência de aconchego na relação, a felicidade e a comunicação (Gao, 2001; Hernandez, 1999; Hernandez \& Oliveira, 2003). A intimidade existe nos relacionamentos em que estão presentes os seguintes elementos: (a) o desejo de promover o bem-estar de outra pessoa; (b) a felicidade de poder compartilhar experiências de vida; (c) o discernimento de respeito mútuo; (d) a compreensão mútua de se manter presente nos momentos difíceis da vida do parceiro; (e) a concepção íntima de compartilhar a vida, assim como bens materiais; (f) a disposição de dar e receber apoio emocional; (g) a capacidade de se comunicar além dos níveis superficiais ou práticos; e (h) o reconhecimento mútuo do valor do parceiro em sua vida.

Paixão (vértice esquerdo do triângulo). A paixão é o elemento que se refere às movimentações que conduzem ao romance, à atração física, à relação sexual (Gao, 2001; Hernandez \& Oliveira, 2003) e aos fenômenos relacionados ao amor propriamente dito. Consiste em fontes motivacionais que levam à experiência apaixonada, como a excitação. Num relacionamento amoroso, as necessidades sexuais podem predominar. De qualquer modo, outras necessidades, tais como auto-estima, sentir-se satisfeito, afiliação, dominância, submissão 


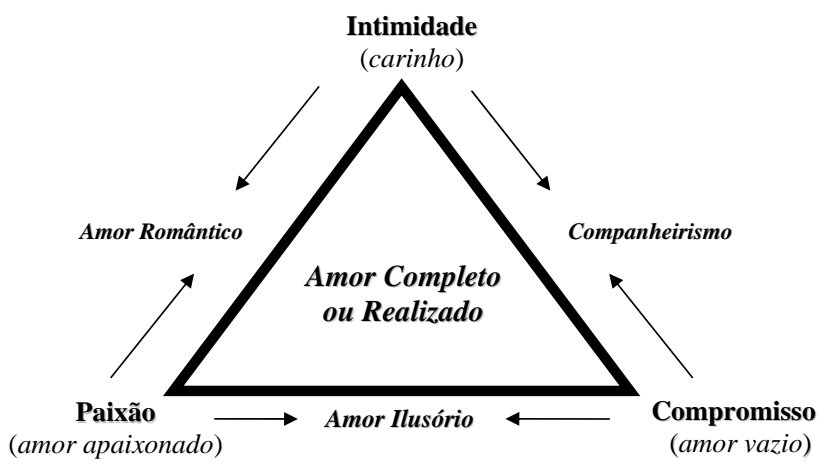

Figura 1. Componentes básicos do amor e suas combinações ou tipos de amor, segundo a Teoria Triangular do Amor, de Sternberg (1997).

e auto-atualização, podem também contribuir para a experiência da paixão (Sternberg, 1997). Dos três elementos, é o mais fácil de ser reconhecido, mas isso não significa que seja o mais fácil de definir ou controlar. Embora a paixão seja uma sensação física, a atividade sexual preenche muitas necessidades emocionais (Hernandez, 1999). Portanto, este componente pode ser descrito como: (a) sensações românticas; (b) atração física e desejo de estar junto; (c) satisfação e contentamento sexual mútuos; e (d) excitação física e emocional.

Compromisso (vértice direito do triângulo). Trata-se, num aspecto mais restrito, de uma decisão por amar o outro, e num aspecto mais abrangente, o compromisso desse alguém para manter este amor (Hernandez \& Oliveira, 2003). Estes dois aspectos do componente compromisso não precisam necessariamente estar juntos; compete amar alguém mesmo que o outro não esteja comprometido a manter este amor ou um pode estar empenhado com o relacionamento reconhecendo que não é amado pela outra pessoa (Sternberg, 1997). O comprometimento é essencial para um relacionamento duradouro e isto inclui (Hernandez, 1999): (a) a certeza de que o que se sente é um tipo especial de amor; (b) a disposição para simbolizar ou articular esse amor de algum modo; (c) a compreensão de que o relacionamento é mais do que um capricho passageiro; e (d) a decisão de investir no relacionamento por um determinado período de tempo ("para sempre", "a longo prazo", etc.).

Os três componentes do amor, embora possam ser vistos como isolados, interagem entre si (Engel et al., 2002; Sternberg, 1986). Por exemplo, uma grande intimidade pode levar a uma grande paixão ou compromisso, assim como o compromisso pode levar a uma grande intimidade ou, com pouca probabilidade, a uma grande paixão (Sternberg, 1997). Apesar de o fato de todos compreenderem partes importantes de um relacionamento amoroso, sua preponderância pode diferenciar de um relacionamento para outro ou no transcorrer do tempo dentro de um mesmo relacionamento (Serrano \& Carreño, 1993).

De acordo com Sternberg $(1986,1997)$, diferentes tipos de amor podem ser gerados, limitando-se às circunstâncias das diferentes combinações dos componentes. Deste modo, os três elementos geram sete possíveis tipos de amor quando estas combinações ocorrem (Engel et al., 2002): (a)
Carinho: surge quando uma pessoa experimenta somente o componente intimidade, havendo ausência dos componentes paixão e compromisso; (b) Amor apaixonado: resulta da vivência do componente paixão e a ausência dos demais; (c) Amor vazio: emana da determinação de um dos indivíduos de estar compromissado com o outro, mas há ausência dos componentes de intimidade e paixão; (d) Amor companheiro (companheirismo): deriva da combinação dos componentes de intimidade e compromisso; (e) Amor ilusório (irreal, insensato): resulta da combinação dos componentes de paixão e compromisso e ausência do componente intimidade; (f) Amor romântico: fruto do acordo entre os elementos paixão e intimidade, com a falta do compromisso; e (g) Amor completo (realizado): é o resultado da combinação plena dos três componentes do amor.

Sternberg (1997) destaca ainda que a geometria deste triângulo depende de dois fatores: da quantidade de amor e do equilíbrio harmônico do amor. Diferenças na quantidade de amor estão representadas por diferentes áreas do triângulo: quanto maior a quantidade de amor, maior será a área do triângulo. Quando há equilíbrio nos três componentes, o triângulo pode ser representado como um amor igualmente equilibrado cuja representação será de um triângulo eqüilátero. $\mathrm{O}$ amor não envolve somente um único triângulo, mas certamente outros, onde somente alguns são de interesse, tanto teórico como prático. Por exemplo, é possível contrastar triângulos ideais com os reais. A pessoa não tem somente um triângulo representando o seu amor por outro, mas também um triângulo concebendo uma pessoa ideal para aquela relação que seria baseada na experiência com outras relações com o mesmo tipo de amor (Hernandez, 1999; Hernandez \& Oliveira, 2003). Também é possível distinguir entre "auto-percepção" e "percepção dos outros". Em outras palavras, o sentimento de uma pessoa num relacionamento pode ou não corresponder ao quão significante é a percepção do outro em relação ao sentimento na mesma relação.

Segundo Sternberg (1997), é importante ressaltar a diferença entre triângulos de sentimento e triângulos de interação (ação). Uma coisa é sentir de uma determinada maneira o significado do outro; e outra coisa é agir de forma consistente com esse sentimento. Cada um dos três componentes do amor tem um conjunto de ações associados. Por exemplo, a intimidade pode 
ser manifesta por meio de ações que visam dividir o tempo com o indivíduo, expressando empatia pelo outro, comunicando-se de forma honesta. Já o compromisso pode ser expresso por meio da fidelidade sexual, engajamento na relação, no casamento. Este autor indica que nem sempre os três componentes do amor fazem parte de um relacionamento afetivo ou possuem peso igual para todos. Este exemplo pode ser verificado no amor pela família que, geralmente, consiste de intimidade e compromisso, sem paixão (Hernandez, 1999), ou das relações em ambiente de trabalho com grande intimidade, mas que nem sempre se transformam em amizades duradouras ou relacionamentos românticos.

O modelo de Sternberg determina propriedades diferentes para os três componentes do amor (Hernandez, 1999; Sternberg, 1997): (1) a intimidade e o compromisso são mais estáveis do que a paixão; (2) é possível exercer um grande controle sobre o compromisso e algum controle sobre a intimidade, mas muito pouco sobre a paixão; (3) o reconhecimento da paixão é sempre alto, enquanto que o reconhecimento da intimidade e do compromisso pode variar; (4) a paixão tem função importante nos relacionamentos breves; (5) a intimidade ocorre com o tempo, e o compromisso depende de um prazo provavelmente maior; (6) a intimidade é comum na maioria dos relacionamentos amorosos (de amantes, da família ou de amigos), já a paixão só é comum nos relacionamentos românticos e o compromisso raramente acontece em outros tipos de relação; e (7) a paixão depende do envolvimento psicofisiológico, enquanto que o compromisso e a intimidade dependem relativamente menos. Contudo, Sternberg (1997) não se limita à teorização, oferecendo um instrumento capaz de capturar as três dimensões do amor.

\section{Escala Triangular do Amor}

Esta medida foi originalmente construída nos Estados Unidos, composta por 36 itens que foram respondidos por 84 adultos. A partir da análise fatorial, correlação item-total, cálculo de consistência interna dos três fatores teorizados e correlação com outras medidas relacionadas com o amor, definiu-se uma nova versão desta medida. Nessa oportunidade, aumentouse o número de itens dos fatores que passou de 12 para 15. Portanto, propôs-se a versão comumente empregada da Escala Triangular do Amor, constituída por 45 itens, subdivididos em três componentes principais do amor, cada um representado por 15 itens (Sternberg, 1997): intimidade (por exemplo, "Sinto que realmente me compreende"), paixão (por exemplo, "Eu não imagino outra pessoa me fazendo tão feliz como ___ me faz") e compromisso (por exemplo, "Espero amar___ por toda minha vida"). Esta versão foi aplicada a 101 adultos, extraindo-se os três fatores por meio de análise fatorial. Quanto ao índice de consistência interna (Alfa de Cronbach) dos três fatores, estes apresentaram valores acima de 0,70 , que têm sido amplamente recomendados (Nunnally, 1991).

Em geral, os estudos que empregam a teoria triangular do amor, de Sternberg, têm relacionado a temática do amor com construtos como os traços de personalidade, a exemplo daquele realizado por Engel et al. (2002). Além disso, sua capacidade descritiva, preditiva e diagnóstica são igualmente avaliadas, como demonstradas no estudo de Serrano e Carreño (1993).
Esta teoria também tem sido analisada em caráter transcultural, aos moldes do verificado em Gao (2001), ao comparar a intimidade, a paixão e o compromisso em amostras de estudantes universitários estadunidenses e chineses envolvidos em relacionamento romântico estável. Nos resultados deste estudo a paixão apresentou-se significativamente mais elevada na amostra estadunidense do que na chinesa, porém as intensidades de intimidade e compromisso não variaram transculturalmente.

Recentemente, em estudo realizado na Holanda por Overbeek, Ha, Scholte, Kemp e Engels (2007), comprovou-se a adequação de uma versão abreviada da Escala Triangular do Amor para utilização com amostra de 435 adolescentes entre 12 e 18 anos de idade. A propósito, os índices de consistência interna (Alfa de Cronbach) foram de 0,87 no fator intimidade, 0,89 em paixão e 0,80 no fator compromisso. Neste caso, realizouse primeiro uma análise fatorial exploratória (Componentes Principais, rotação varimax), reunindo 19 itens. Posteriormente, realizaram uma análise fatorial confirmatória, considerando os mesmos participantes, encontrando como mais favorável uma estrutura com os três fatores antes listados, cujos índices de ajuste foram os seguintes: $\chi^{2}(74)=216,90 ; p<0,001 ; C F I=0,90 \mathrm{e}$ $R M S E A=0,08$. Cabe, entretanto, ponderar que esta análise não procurou replicar os estudos em amostras independentes, tendo se limitado também ao estudo do amor entre adolescentes.

Embora a versão de 45 itens deste instrumento tenha sido previamente adaptada para o contexto brasileiro por Hernandez (1999) e, mais recentemente, reavaliado por Cassepp-Borges e Teodoro (2007), constata-se que as amostras utilizadas se limitaram ao sul do país. Neste contexto cultural as pessoas costumam apresentar um padrão de relacionamento mais pautado por valores individualistas, priorizando a realização pessoal e a privacidade mais do que a afetividade e a convivência (Gouveia, Albuquerque, Clemente \& Espinosa, 2002). Nesse sentido, pensou-se em realizar o presente estudo, cujo objetivo principal foi conhecer os parâmetros psicométricos (validade fatorial e consistência interna) da Escala Triangular do Amor no contexto paraibano. Além disso, pretendeu-se avaliar a possibilidade de contar com uma versão reduzida daquela que propõe Sternberg (1997), o que pode favorecer estudos que envolvam múltiplas amostras e medidas (Gosling, Rentfrow, \& Swann Jr., 2003). Portanto, desenvolveu-se a pesquisa cujo método é descrito a seguir.

\section{Método}

\section{Amostra}

Participaram desta pesquisa unicamente estudantes universitários da cidade de João Pessoa (PB), de ambos os sexos e que tinham uma relação heterossexual estável. Foram aplicados 610 questionários, sendo que deste total a maioria foi do sexo feminino (69,4\%), solteira (82,6\%) e heterossexual (94,9\%), com idade média de 23,4 anos ( $d p=6,35$; amplitude de 17 a 56 anos). Dos que não eram casados / conviventes $(13,1 \%)$, a maioria encontrava-se namorando fixo $(41,4 \%)$. No que diz respeito à religião, a maior parte disse ser católica (66\%). Quanto à classe 
socioeconômica, estes se percebiam predominantemente como pertencentes à classe média $(49,2 \%)$. Esta foi uma amostra de conveniência, não-probabilística; participaram aqueles que, contatados em sala de aula, aceitaram participar do estudo.

Tendo-se em conta este grupo de participantes e o construto (amor) ora avaliado, decidiu-se impor algumas restrições para formar a amostra definitiva. Portanto, contou-se exclusivamente com os respondentes que mantinham uma relação heterossexual estável, estabelecendo as seguintes regras de exclusão: (1) não participaram os respondentes que indicaram ser solteiros, sem qualquer relacionamento ou com namoro ocasional, e (2) os que se declararam homossexuais ou bissexuais.

Neste sentido, todos os participantes da amostra definitiva contavam com relacionamento heterossexual estável (casado, ou com namoro fixo), totalizando 307 respondentes. Deste total, a maioria foi do sexo feminino $(69,4 \%)$ e solteira $(73 \%)$. Neste caso, majoritariamente namorando fixo $(85,5 \%)$. A idade média dos participantes foi de 23,4 anos $(d p=6,22$; amplitude de 17 a 56 anos), e estes predominantemente se declararam católicos $(66,4 \%)$ e pertencentes à classe sócio-econômica média $(49,5 \%)$. Esta amostra final manteve as características demográficas presentes na amostra inicial $(n=610)$.

\section{Instrumentos}

Os respondentes receberam um questionário constando de duas partes:

Escala Triangular doAmor. Esta medida, como anteriormente foi descrita, é composta por 45 itens, distribuídos equitativamente em três fatores: intimidade, paixão e compromisso. Os espaços em branco não precisam ser preenchidos pelos respondentes (por exemplo, "Sinto que ___ realmente me compreende"); estes precisam apenas imaginar que neles figura o nome do(a) namorado(a), noivo(a), esposo(a) ou companheiro(a). Os itens são respondidos em uma escala com 9 pontos, com os extremos: 1 (Não me descreve nada) e 9 (Me descreve totalmente), expressando assim o nível em que a afirmação se aplica ao relacionamento do(a) respondente com o(a) outro(a). Dois psicólogos bilíngües, independentemente, traduziram a versão original desta escala do inglês para o português; um terceiro psicólogo, também bilíngüe, comparou as duas traduções e confrontou-as com a de Hernandez (1999), chegando à versão que ora se apresenta.

Perguntas demográficas. Incluíram-se perguntas de caráter sócio-demográfico (por exemplo, sexo, idade, estado civil e orientação sexual), procurando retratar o perfil dos participantes do estudo. Finalmente, solicitou-se aos participantes que indicassem como se percebiam em termos de classe socioeconômica, empregando-se uma escala de sete pontos, variando desde 1 (classe baixa) até 7 (classe alta).

\section{Procedimento}

Os departamentos dos cursos universitários foram contatados pelos aplicadores tendo em mãos uma carta de apresentação à coordenação / direção de cada instituição de ensino superior. O questionário foi de auto-aplicação e esta aconteceu em ambiente coletivo de sala de aula, porém as respostas foram dadas individualmente. Informou-se aos participantes que se tratava de conhecer algo mais acerca de suas relações interpessoais e afetivas. Enfatizou-se o caráter confidencial e sigiloso de sua participação, indicando que não existiam respostas certas ou erradas, solicitando assim que respondessem da forma mais sincera possível. Um termo de consentimento livre e esclarecido foi lido e assinado por cada um dos participantes, sendo depois colocado em um envelope específico, procurando desvinculálo das suas respostas. Somente depois deste procedimento os participantes recebiam o questionário, acompanhado de esclarecimentos por parte dos aplicadores quanto à forma de proceder. Por fim, foram realizados os devidos agradecimentos. Um tempo médio de 15 minutos foi necessário para responder ao conjunto de perguntas.

\section{Tabulação e análise dos dados}

O SPSS (versão 15) foi utilizado para tabulação e análise dos dados. Utilizaram-se estatísticas descritivas (medidas de tendência central e dispersão, distribuição de freqüência) para caracterizar os participantes do estudo. Uma análise de Componentes Principais (PC) foi empregada a fim de compreender a estrutura da medida de amor. Além disso, comprovou-se a consistência interna dos componentes por meio do Alfa de Cronbach. Uma MANOVA para medidas repetidas foi realizada para comparar as pontuações dos participantes nos componentes do amor; uma MANOVA inter-fatores também foi efetuada com o fim de conhecer em que medida suas pontuações em tais componentes poderiam variar em razão de características demográficas (sexo, estado civil e classe social).

\section{Resultados}

\section{Análise exploratória do instrumento}

De acordo com os objetivos da presente pesquisa e com a finalidade de replicar as análises estatísticas dos estudos realizados nos Estados Unidos (Sternberg, 1997) e no Brasil (Cassepp-Borges \& Teodoro, 2007; Hernandez, 1999), procurou-se inicialmente conhecer evidências de validade fatorial e consistência interna da Escala Triangular do Amor. Como anteriormente exposto, embora este instrumento tenha sido previamente adaptado para o Brasil, o foi para um contexto cultural particular. Contudo, partindo do instrumento original (Sternberg, 1997), procurou-se definir uma versão reduzida post hoc a partir dos resultados do primeiro estudo de adaptação brasileira (Hernandez, 1999), considerando para cada componente desta medida os cinco itens com maiores saturações. Neste caso, tiveram-se em conta dois critérios: (1) o item deveria ter saturação mínima de 0,50 em um único componente, e (2) pertencer ao componente ao qual teoricamente representaria. Esta é uma solução mais parcimoniosa, permitindo que em estudos futuros se avalie a possibilidade de que venha a substituir a versão original desta escala.

Previamente à análise fatorial, comprovou-se a adequação de se proceder a este tipo de análise, tendo sido observados indicadores favoráveis: $K M O=0,92$ e teste de esfericidade de Bartlett, $\chi_{(105)}^{2}=2.663,49 ; p<0,001$. A propósito, decidiu-se realizar uma análise de Componentes Principais, fixando a 
extração de três componentes, com rotação varimax, primando por uma estrutura simples. Estes resultados podem ser vistos na Tabela 1.
O conjunto dos três componentes explicou $67,7 \%$ da variância total. Tomando-se como critério que as saturações deveriam ser iguais ou superiores a 0,50 para que o item fosse

Tabela 1

Estrutura fatorial da Escala Triangular do Amor

\begin{tabular}{|c|c|c|c|c|}
\hline \multirow[b]{2}{*}{ Item } & \multirow[b]{2}{*}{ Conteúdo do item } & \multicolumn{3}{|c|}{ Fatores } \\
\hline & & $\mathbf{I}$ & II & III \\
\hline 05 & Espero amar ___ por toda minha vida. & 0,81 & 0,09 & 0,29 \\
\hline 10 & Eu vejo meu relacionamento com ___ como permanente (duradouro). & 0,75 & 0,21 & 0,31 \\
\hline 13 & Não imagino terminar o relacionamento com ___. & 0,74 & 0,29 & 0,18 \\
\hline 18 & Estou seguro(a) do meu amor por $\ldots$ _. & 0,72 & 0,36 & 0,20 \\
\hline 23 & $\begin{array}{l}\text { Eu não poderia deixar que nada interferisse de algum modo meu } \\
\text { compromisso com }\end{array}$ & 0,69 & 0,38 & 0,22 \\
\hline 12 & Só em olhar para ___ é excitante. & 0,19 & 0,79 & 0,15 \\
\hline 24 & Acho ___ muito atraente. & 0,14 & 0,77 & 0,30 \\
\hline 36 & Eu particularmente gosto do contato físico com $\ldots$. & 0,25 & 0,71 & 0,19 \\
\hline 29 & Sonho de olhos abertos com ___. & 0,39 & 0,70 & 0,17 \\
\hline 40 & Meu relacionamento com ___ é apaixonante. & 0,46 & 0,66 & 0,34 \\
\hline 07 & Posso contar com ___ na hora que eu necessitar. & 0,20 & 0,09 & 0,81 \\
\hline 04 & Eu recebo considerável suporte emocional de ___. & 0,21 & 0,13 & 0,80 \\
\hline 43 & Sinto que ___ realmente me compreende. & 0,30 & 0,33 & 0,72 \\
\hline 35 & Me comunico bem com ___. & 0,21 & 0,31 & 0,69 \\
\hline 45 & Sinto que realmente posso confiar em $\ldots$ & 0,25 & 0,35 & 0,57 \\
\hline \multicolumn{2}{|c|}{ Número de Itens } & $\begin{array}{l}5 \\
354\end{array}$ & $\begin{array}{l}5 \\
340\end{array}$ & 5 \\
\hline \multicolumn{2}{|c|}{ \% Variância } & 23,6 & 22,7 & 21,4 \\
\hline \multicolumn{2}{|c|}{ Alfa de Cronbach } & 0,88 & 0,87 & 0,86 \\
\hline
\end{tabular}

Nota. Itens em negrito foram considerados para a interpretação do componente. Identificação dos fatores: $\mathrm{I}=$ Compromisso; II = Paixão; e III = Intimidade.

considerado como pertencente ao componente, encontrou-se a seguinte configuração:

Componente I. Este primeiro componente apresentou valor próprio (eigenvalue) de 3,54, sendo responsável pela explicação de 23,6\% da variância total. Compôs-se de cinco itens, com saturações variando de 0,69 ("Eu não poderia deixar que nada interferisse de algum modo meu compromisso com ___") a 0,81 ("Espero amar___ por toda minha vida"), parecendo clara sua interpretação: diz respeito ao componente compromisso do amor. Sua consistência interna (Alfa de Cronbach) se situou em 0,88 .

Componente II. Este componente apresentou valor próprio de 3,40 , explicando $22,7 \%$ da variância total. Cinco itens o representaram, com saturações variando de 0,66 ("Meu relacionamento com___é apaixonante”) a 0,79 ("Só em olhar para __ é excitante"). Pode-se interpretá-lo como sendo o componente do amor denominado de paixão, que apresentou consistência interna (Alfa de Cronbach) de 0,87.

Componente III. Este último componente apresentou valor próprio de 3,21 , correspondendo à explicação de $21,4 \%$ da variância total. Compôs-se de cinco itens, com saturações variando de 0,57 ("Sinto que realmente posso confiar em __") a 0,81 ("Posso contar com ___ na hora que eu necessitar"). De acordo com a semântica destes itens, pode-se nomeá-lo como intimidade. Seu Alfa de Cronbach se situou em 0,86.

Em resumo, parece haver evidências de validade fatorial e consistência interna da versão reduzida da Escala Triangular do Amor, ao menos para o contexto em que a pesquisa foi realizada. Avaliando a possibilidade de um fator geral de amor, realizou-se ainda uma análise de Componentes Principais com o critério de extração de uma única dimensão, considerando o conjunto dos 15 itens, resultantes das análises anteriormente descritas. Esta apresentou valor próprio de 7,61, explicando 50,7\% da variância total, com saturações acima de 0,60 e Alfa de Cronbach de 0,93. Portanto, pode-se também ter em conta esta pontuação total, embora a teoria suponha três fatores de primeira ordem.

\section{Componentes do amor e características demográficas}

Inicialmente, efetuou-se uma MANOVA para medidas repetidas, procurando comparar as pontuações dos participantes 
nos três componentes do amor: compromisso $(m=6,8 ; d p=$ $1,94)$, paixão $(m=6,9 ; d p=1,81)$ e intimidade $(m=7,0 ; d p$ $=1,73$ ), não tendo sido observada diferença estatisticamente significativa $\left[\right.$ Lambda de Wilks $=0,98 ; F_{(2,298)}=2,26 ; p=$ $0,11]$. Além disso, executou-se uma MANOVA inter-fatores, com o propósito de conhecer em que medida as pontuações dos participantes nos componentes do amor (compromisso, paixão e intimidade) poderiam variar em razão de características demográficas: sexo, estado civil e classe social. No caso, foi constatado efeito principal unicamente da variável sexo [Lambda de Wilks $\left.=0,95 ; F_{(3,196)}=3,62 ; p=0,014\right]$. As diferenças foram observadas apenas em relação ao componente do amor compromisso $\left[F_{(1 / 198)}=4,04 ; p=0,046\right]$, em que as mulheres apresentaram média superior $(m=6,9)$ à dos homens $(m=5,8)$. Efeitos de interação foram observados entre sexo e classe social $\left[F_{(1 / 198)}=5,31 ; p=0,02\right]$ no fator intimidade, e entre sexo, classe social e estado civil $\left[F_{(1 / 198)}=4,19 ; p=0,04\right]$ no fator compromisso. Contudo, quando realizadas as comparações por meio do teste post hoc de Bonferroni, nenhuma diferença se revelou estatisticamente significativa.

\section{Discussão}

O objetivo principal deste estudo foi contribuir para a adaptação da Escala Triangular do Amor para o contexto brasileiro, conhecendo evidências de sua validade fatorial e consistência interna entre estudantes universitários paraibanos. Alternativamente, procurou-se definir uma versão abreviada desta medida, embora prezando pela adequação dos seus parâmetros psicométricos. Confia-se que este propósito geral tenha sido alcançado. Não obstante, não é possível fechar os olhos para o fato de que a amostra considerada não representa toda a Paraíba, nem mesmo a cidade em que os dados foram coletados. Mas, como ficou evidente, o interesse não era generalizar os resultados, e sim conhecer uma estrutura fatorial, com o que o tamanho da amostra $(n=307)$ pode ser considerado satisfatório (Gorsuch, 1983). Deste modo, procura-se a seguir discutir os principais resultados.

\section{Estrutura fatorial e consistência interna}

Coerente com a literatura (Cassepp-Borges \& Teodoro, 2007; Hernandez, 1999; Sternberg, 1997), confirmaram-se evidências de validade fatorial desta medida. Tomando em conta o estudo realizado por Hernandez (1999), procurou-se contar com uma versão abreviada da Escala Triangular do Amor. No caso, teve-se o cuidado de que o item figurasse no seu componente teórico de pertença, apresentando saturação superior a 0,50, que é considerada como de significância prática, sendo, portanto, substancial o bastante para garantir uma ação coerente e resguardar a consistência teórica da medida (Hair, Anderson, Tatham, \& Black, 2005). Tendo em mente estes aspectos, logrouse chegar a uma versão com 15 itens, os quais foram distribuídos eqüitativamente entre os três componentes do amor que foram teorizados por Sternberg (1997). Considerar um fator geral do amor, embora possa parecer contrário ao modelo triangular tratado, é prática indicada pelo próprio Sternberg (1997), ao sugerir um índice de consistência interna para o conjunto dos itens de sua medida; também Cassep-Borges e Teodoro (2007) tomam tal decisão. A justificativa para tanto parece plausível: são três componentes estreitamente associados entre si que podem convergir para definir um sentimento pleno, de amor completo (Engel et al., 2002).

O formato abreviado desta medida é, sem dúvida, um atrativo, principalmente quando considerado o contexto de pesquisas transculturais (Gosling et al., 2003). Contudo, esta não é a única vantagem; Cassep-Borges e Teodoro (2007) perceberam que contar com uma versão reduzida poderia acabar com o problema dos itens que saturam em mais de um fator. No caso, eles propuseram uma versão com 18 itens distribuídos entre os três fatores do amor. Mas, reconhecem tais autores, adotar a estratégia de reduzir o número de itens pode fazer com que a escala perca em fidedignidade (consistência interna). Contrariamente, eles encontraram Alfas de Cronbach equivalentes àqueles observados com a versão original desta medida.

Este achado foi igualmente constatado no presente estudo, quando os três componentes específicos e o geral, compreendendo o somatório dos 15 itens, apresentaram Alfas acima de 0,80 , atendendo à rule of thumb que sugere o valor de 0,70 como indicativo de que se cumpra este parâmetro psicométrico (Nunnally, 1991). Estes resultados vão na mesma direção daqueles descritos por Sternberg (1997) e Hernandez (1999), os quais tiveram em conta a versão completa desta medida (45 itens). Destaca-se igualmente que os coeficientes de consistência interna da versão ora apresentada são equivalentes aos reportados por Overbeek et al. (2007), que também propuseram uma versão reduzida desta medida, composta por 19 itens e dirigida a adolescentes; de fato, o Alfa de Cronbach do componente compromisso foi maior no presente estudo do que naquele desses autores $(\propto=0,80)$.

\section{O sexo dos participantes e os componentes do amor}

A variável sexo pareceu preponderante para explicar o tipo de amor que mais caracteriza a relação dos participantes deste estudo. Foi o caso, especificamente, do compromisso, em que as mulheres apresentaram média mais elevada do que os homens. Lembrando, este é um componente importante para o desenvolvimento e contínuo equilíbrio dos relacionamentos estáveis (Adams \& Jones, 1997), mas, não parece ser igualmente compartilhado por ambos os sexos. Segundo Kim e Hatfield (2004), o amor para os homens envolve mais paixão, já para as mulheres abarca, sobretudo, o companheirismo, típico da intimidade, mas que pode ocorrer como conseqüência do comprometimento estabelecido na relação (ver também Sternberg, 1997).

É possível que fique mais evidente a importância do compromisso para as pessoas do sexo feminino quando são consideradas, por exemplo, as diferenças mentais entre homens e mulheres. De acordo com Baron-Cohen (2004), o cérebro masculino é predominantemente sistemático, enfocando elementos práticos em uma relação, como pode advir do prazer inerente à paixão; o cérebro feminino, por outro lado, endossa a empatia com a finalidade de compreender, prever o comportamento do outro e estabelecer um envolvimento 
emocional. Este tipo de "raciocínio empatizador" pode vir a ser um facilitador para maior compromisso demonstrado pelas mulheres, que é, por sua vez, tão necessário à manutenção e convivência amorosa de um casal (Hernandez, 1999; Sternberg, 1997; Yela, 1997).

Em resumo, parece justificável pensar na versão reduzida da Escala Triangular do Amor como psicometricamente adequada, reforçando estudos prévios que tiveram em conta a versão original desta mesma medida (Hernandez, 1999; Overbeek et al., 2007; Sternberg, 1997) ou sua versão abreviada (Cassepp-Borges \& Teodoro, 2007). Portanto, tal medida poderá ser empregada em pesquisas futuras que pretendam conhecer os antecedentes e conseqüentes do amor enquanto um construto psicológico. A propósito de estudos futuros, faz-se um esforço a seguir no sentido de indicar prováveis direções.

\section{Estudos e direções futuras}

Embora reunindo parâmetros psicométricos que apontam evidências favoráveis de sua validade fatorial e consistência interna, as pontuações obtidas na Escala Triangular do Amor podem revelar algo de desejabilidade social. É provável que quando se solicite ao respondente que pense em alguém que ama, a tendência seja de idealizá-lo. Mas, não seria este um elemento próprio do amor? A resposta, certamente, seria um contundente sim, no sentido de que se idealiza o objeto ou ser amado (Kemper $\&$ Bologh, 1980). Entretanto, há que se diferenciar este aspecto inerente ao amor de um presumível viés de resposta, que pode ser entendido em termos de desejabilidade social. Portanto, neste sentido, talvez fosse recomendável ter em conta este aspecto, incluindo uma medida a respeito deste construto, permitindo ao menos controlá-la estatisticamente, evitando confundir o seu efeito com o que poderia ser propriamente a pontuação nos componentes do amor.

De acordo com Alferes (2002), semelhante ao que ocorre com outros modelos acerca do amor, a Teoria Triangular do Amor depara-se com algumas limitações, mesmo que sob o ponto de vista descritivo e heurístico seja, nomeadamente, predominante para o estudo sistemático dos relacionamentos românticos. Sua principal limitação, na visão desse autor, é o fato de esse modelo não se basear diretamente na análise dos processos evolutivos e psicossociais envolvidos nas relações amorosas. Talvez este aspecto demande, futuramente, repensar a medida ora discutida, atentando para aspectos mais evolutivos ou de cunho social. Contudo, esta não é uma tarefa fácil, exigindo, provavelmente, a própria reformulação ou o aprimoramento do modelo teórico de Sternberg (1997).

Quanto ao aspecto antes assinalado, é destacável a contribuição de Yela (2006). Este autor reconhece, por exemplo, a necessidade de se dividir o componente do amor denominado como paixão, distinguindo paixão romântica e paixão erótica. Estes componentes, embora enfocando uma mesma dimensão subjacente, regem-se por princípios diferentes, algo como a divisão entre amor (o sentido sublime da expressão, sendo duradouro, que pode existir inclusive sem o outro) e o sexo (algo mais pragmático, carnal, temporário).

Finalmente, quanto ao que fazer acerca dos conseqüentes do amor, cabem diversas frentes de pesquisa. Poderia ser importante, por exemplo, conhecer em que medida os três componentes do amor podem se correlacionar com o ciúme romântico. De modo similar, embora se imagine que o amor implica em nãotraição, será que a vivência de um dos tipos do amor não faria mais provável romper com esta idéia? Por exemplo, a paixão parece ser um elemento mais fugaz do amor, assentando-se em relações mais carnais, fisiológicas e pragmáticas (Sternberg, 1997). Deste modo, talvez houvesse maior tendência de pessoas que "sentem" este tipo de amor virem a trair o(a) parceiro(a). Igualmente, mesmo sem sentir este tipo de amor, mas as pessoas mais propensas a vivê-lo, no momento em que dele têm falta, não se dignam a pautar seu relacionamento por compromisso e intimidade, buscando uma pessoa que possa satisfazer esta deficiência de amor.

\section{Referências}

Adams, J. M., \& Jones, W. H. (1997). The conceptualization of marital commitment: An integrative analysis. Journal of Personality and Social Psychology, 72, 1177-1196.

Alferes, V. R. (2002). Atracção interpessoal, sexualidade e relações íntimas. In J. Vala \& M. B. Monteiro (Orgs.), Psicologia Social (pp. 125-158). Lisboa: Fundação Calouste Gulbenkian.

Baron-Cohen, S. (2004). Diferença essencial: A verdade sobre o cérebro de homens e mulheres. Rio de Janeiro: Objetiva.

Bystronski, B. (1995). Teorias e processos psicossociais da intimidade interpessoal. In A. Rodrigues (Org.), Psicologia Social para principiantes: estudo da interação humana (pp. 59-90). Petrópolis: Vozes.

Cassepp-Borges, V. \& Teodoro, M. L. M. (2007). Propriedades psicométricas da versão brasileira da Escala Triangular do Amor de Sternberg. Psicologia: Reflexão e Crítica, 20, 513-522.

Engel, G., Olson, K. R., \& Patrick, C. (2002). The personality of love: Fundamental motives and traits related to components of love. Personality and Individual Differences, 32, 839-853.

Gao, G. (2001). Intimacy, passion, and commitment in Chinese and US American romantic relationships. International Journal of Intercultural Relations, 25, 329-342.

Google Acadêmico. (2009). Love Attitude Scale / Triangular Love Scale. Consulta realizada em 03 de maio de 2009, no site http://scholar.google.com.br/ scholar? $\mathrm{q}=\% 22$.

Gorsuch, R. L. (1983). Factor analysis. Hillsdale, New Jersey: Lawrence Erlbaum.

Gosling, S. D., Rentfrow, P. J., \& Swann Jr., W. B. (2003). A very brief measure of the Big Five personality domains. Journal of Research in Personality, 37, 504-528.

Gouveia, V. V., Albuquerque, F. J. B., Clemente, M., \& Espinosa, P. (2002). Human values and social identities: A study in two collectivist cultures. International Journal of Psychology, 37, 333-342.

Hair, J. F. J., Anderson, R. E., Tatham, R. L., \& Black, W. C. (2005). Análise multivariada de dados. Porto Alegre: Bookman.

Hendrick, C. \& Hendrick, S. (1986). A theory and method of love. Journal of Personality and Social Psychology, 50, 392-402.

Hernandez, J. A. E. (1999). Validação da estrutura da Escala Triangular do Amor: análise fatorial confirmatória. Aletheia (Rio Grande do Sul), 9, 15-26

Hernandez, J. A. E., \& Oliveira, I. M. B. de (2003). Os componentes do amor e a satisfação. Psicologia: Ciência e Profissão, 21, 58-69.

Kemper, T. D., \& Bologh, R. W. (1980). The ideal love object: Structural and family sources. Journal of Youth and Adolescence, 9, 33-48.

Kim, J., \& Hatfield, E. (2004). Love types and subjective well-being: A crosscultural study. Social Behavior and Personality, 32, 173-182. 
Lee, J. A. (1973). Colors of love: An exploration of the ways of loving. Nova York: New Press.

Lee, J. A. (1988). Love styles. In R. J. Sternberg \& M. H. Barnes (Orgs.), The psychology of love (pp. 38-67). New Haven, Connecticut: Yale University Press.

Nunnally, J. C. (1991). Teoría psicométrica. México: Trillas.

Overbeek, G., Ha, T., Scholte, R., Kemp, R., \& Engels, R. C. M. E. (2007). Brief report: intimacy, passion, and commitment in romantic relationships Validation of a 'triangular love scale' for adolescent. Journal of Adolescence, 30, 523-528.

Serrano, G. \& Carreño, M. (1993). La Teoría de Sternberg sobre el amor: análisis empírico. Psicothema, 5, 151-167.

Sternberg, R. J. (1986). A triangular theory of love. Psychological Review, 93,
119-135.

Sternberg, R. J. (1997). Construct of a triangular love scale. European Journal of Psychology, 27, 313-335.

Sternberg, R. J. (1998). Love is a story: A new theory of relationships. Nova York: Oxford.

White, J. K., Hendrick, S. S., \& Hendrick, C. (2004). Big five personality variables and relationship constructs. Personality and Individual Differences, 37, 1519-1530.

Yela, C. (1997). Curso temporal de los componentes básicos del amor a lo largo de la relación de pareja. Psicothema, 9, 1-15.

Yela, C. (2006). The evaluation of love: Simplified version of the scales for Yela's Tetrangular Model based on Sternberg's model. European Journal of Psychological Assessment, 22, 21-27.

Valdiney Veloso Gouveia, doutor em Psicologia Social pela Universidade Complutense de Madri, Espanha, é professor Adjunto IV na Universidade Federal da Paraiba e pesquisador 1B do CNPq. Endereço para correspondência: Universidade Federal da Paraíba; Centro de Ciências Humanas, Letras e Artes; Departamento de Psicologia; João Pessoa, PB; 58.051-900. E-mail: vvgouveia@gmail.com ou vvgouveia@pesquisador. cnpq.br

Patrícia Nunes da Fonsêca, doutora em Psicologia Social pela Universidade Federal da Paraíba, é professora adjunta do Centro Universitário de João Pessoa (UNIPE). E-mail: patynfonseca@uol.com.br

Jane Palmeira Nobrega Cavalcanti, mestre em Psicologia Social pela Universidade Federal da Paraíba, é professora assistente da Faculdade do Vale do Ipojuca (FAVIP). E-mail: jane.palmeira@terra.com.br Pollyane K. da Costa Diniz é mestre em Psicologia Social, pela Universidade Federal da Paraíba. E-mail:pollyanediniz@gmail.com

Luciana Chacon Doria é graduada em Psicologia, pela Universidade Federal da Paraíba. E-mail: 1chacondoria@gmail.com 